\title{
Effect of fibre spinning conditions on the electrical properties of cellulose and carbon nanotube composite fibres spun using ionic liquid as a benign solvent
}

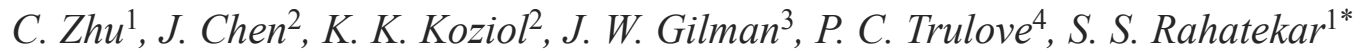 \\ ${ }^{1}$ Advanced Composites Centre for Innovation and Science (ACCIS), Aerospace Engineering, University of Bristol, \\ BS8 1TR Bristol, UK \\ ${ }^{2}$ Department of Materials Science \& Metallurgy, University of Cambridge, CB3 0FS Cambridge, UK \\ ${ }^{3}$ Material Measurement Laboratory, Materials Science Division, National Institute of Standards and Technology, \\ MD 20899 Gaithersburg, USA \\ ${ }^{4}$ Chemistry Department, U.S. Naval Academy, MD 21402 Annapolis, USA
}

Received 12 August, 2013; accepted in revised form 21 October 2013

\begin{abstract}
The aim of this study was to develop electrically conductive fibres from cellulose. To achieve this, the effect of fibre extrusion speed and fibre winding speed on the degree of alignment of multiwall carbon nanotubes (MWNTs), as well as the resulting electrical properties of the cellulose/MWNTs composite fibres were systematically studied. 1-Ethyl-3Methylimidazolium Acetate (EMIMAc) was used as an environmentally benign solvent for dissolution of cellulose as well as for dispersion of MWNTs in the solution dope. To achieve good dispersion of MWNTs in the cellulose solution dope, MWNTs were non-covalently functionalized using carboxymethyl cellulose (CMC). This significantly improved the dispersion of MWNTs in the solution dope. The degree of alignment of MWNTs after both fibre extrusion and winding, was studied using scanning electron microscopy (SEM) and wide angle X-ray diffraction (WAXD). The degree of alignment of MWNTs was correlated with the electrical properties. A significant decrease in electrical conductivity accompanied the increase in degree of alignment of MWNTs when fibres were spun with higher extrusion speed. The decrease was also measured when fibres were spun with higher winding speed using a constant extrusion speed. However, the decrease in conductivity due to winding was low relative to fibres spun at highest extrusion speed.
\end{abstract}

Keywords: nanocomposites, cellulose, ionic liquid, fibre spinning, conductivity

\section{Introduction}

Electrically conductive polymer textile fibre is desirable in applications such as electronic textiles (smart shirt) [1] which can measure body temperature and heart rate, as well as in textiles which can be used as electrically conducting implantable electrodes for brain stimulation [2]. Carbon nanotubes offer a great potential to be used as electrically conducting inclusions in textiles due to their excellent electrical conductivity and high aspect ratio [3]. Many researchers have studied the properties of nylon/nanoparticle [4] and $\mathrm{PBO} /$ carbon nanotube textiles [5], as well as others with improved electrical properties $[6,7]$. Cellulose textiles reinforced with carbon nanotubes can offer a combination of good biocompatibility, electrical conductivity, and the ability to be easily spun and woven into textile fabrics [8]. However, there are three main challenges to achieving highly conductive cellulose/carbon nanotubes composite fibres, namely, 1) dissolution and fibre spinning of cellulose using a benign solvent, 2) uniform dispersion of carbon nanotubes

\footnotetext{
${ }^{*}$ Corresponding author, e-mail: Sameer.Rahatekar@bristol.ac.uk (C) BME-PT
} 
in cellulose and 3) avoiding alignment of carbon nanotubes (which will result in lower electrical conductivity) during the fibre spinning process. To overcome the first challenge, room temperature ionic liquids such as EMIMAc can be employed as environmentally benign solvent, which is safer and easier to handle than traditionally used solvents such as carbon disulphide [9], sulphuric acid [10] and $N$-methylmorpholine- $N$-oxide (NMMO) [11]. A number of researchers have used ionic liquids for fibre stretching/spinning of cellulose [12-18], wool $[19,20]$, chitin [21-24] and other natural polymers [25-28], as well as composite fibres of cellulose [8, 29]. Despite this progress, the remaining two challenges, uniform dispersion of carbon nanotube in cellulose solution dope and avoidance of high degree of alignment of carbon nanotubes during fibre spinning, still remain largely unaddressed. In the present study, we look at methods of improving the dispersion of carbon nanotubes in EMIMAc and in cellulose solution dope. We also carefully study the effect of fibre spinning parameters such as fibre extrusion speed and fibre winding speed on the electrical conductivity of the cellulose/carbon nanotube composite fibres. This study will be specifically useful for improving the degree of dispersion of carbon nanotubes in cellulose fibres, electrical conductivity of cellulose/nanotubes composite fibres and their potential use for other applications such as conducting textiles and for implantable electrodes for stimulation of tissues.

\section{Experimental}

\subsection{Materials and methods}

The ionic liquid (IL) 1-Ethyl-3-Methylimidazolium Acetate (EMIMAc) and carboxymethyl cellulose (CMC) were obtained from Sigma-Aldrich (419273, Gillingham, UK). The cellulose pulp sheets with a degree of polymerisation (DP) of 890 were provided by Rayonier (Jacksonville, United States). The MWNT forest, with average MWNT outer diameter of $80 \mathrm{~nm}$ and length of $1 \mathrm{~mm}$ [8], were kindly supplied by Department of Materials Science \& Metallurgy in University of Cambridge with synthesis details and characterisation published elsewhere [30].

A magnetic stirrer hotplate (Fisher scientific, Loughborough, UK) with oil bath was used for solution preparation. The dissolution processing was carried out in a hood. The cellulose pulp sheets were fine chopped into small pieces with scissors and ground with a grinder.

\subsection{CMC/MWNTs preparation}

$300 \mathrm{mg}$ CMC was grounded uniformly in a few millilitres of distilled water using mortar and pestle. Then $300 \mathrm{mg}$ MWNTs forest was mixed and grounded together with the $\mathrm{CMC} / \mathrm{H}_{2} \mathrm{O}$ suspension. The MWNTs $/ \mathrm{CMC} / \mathrm{H}_{2} \mathrm{O}$ mixture was added in a $250 \mathrm{~mL}$ conical flask with $200 \mathrm{~mL}$ distilled water, and sonicated for $30 \mathrm{~min}$ using $40 \%$ amplitude of power at $80^{\circ} \mathrm{C}$ with stirring at $10.5 \mathrm{rad} / \mathrm{s}$ for $24 \mathrm{~h}$ until all water evaporated, leaving only dry and thin CMC/MWNTs film. The dry CMC/MWNTs film was added into $20 \mathrm{~g}$ EMIMAc and heated at $80^{\circ} \mathrm{C}$ with stirring at $10.5 \mathrm{rad} / \mathrm{s}$ for $2 \mathrm{~h}$, then kept stirred without heating for $24 \mathrm{~h}$ to get the uniform $15 \mathrm{mg} / \mathrm{g}$ concentration MWNTs/EMIMAc suspension.

\subsection{Fibre spinning}

For fibre spinning, we used 0.08 mass fraction cellulose in EMIMAc to make high viscosity (415.5 Pa·s) solution, which was easily spun. $2 \mathrm{~g}$ cellulose ( 0.08 mass fraction with respect to the total amount of $25 \mathrm{~g}$ EMIMAc) was added into $11.66 \mathrm{~g}$ EMIMAc in an $80 \mathrm{~mL}$ glass reagent bottle and heated at $85^{\circ} \mathrm{C}$ with stirring at $10.5 \mathrm{rad} / \mathrm{s}$ for $2 \mathrm{~h}$. Then $13.34 \mathrm{~g}$ MWNTs/EMIMAc suspension (0.10 mass fraction MWNTs with respect to cellulose) was added into the cellulose/ EMIMAc solution and heated at $85^{\circ} \mathrm{C}$ with stirring at $10.5 \mathrm{rad} / \mathrm{s}$ for $5 \mathrm{~h}$.

After complete dissolution, the MWNTs/cellulose/ EMIMAc fibre solution was transferred into a $20 \mathrm{~mL}$ luer lock syringe (Terumo, UK). The solution in syringe was vacuumed in a vacuum oven at $80^{\circ} \mathrm{C}$ for 16 hours before spinning. Lab-built spinning equipment, which consisted of a syringe pump, a water bath and a winding drum with monitor, was used for fibre spinning. Two different fibre spinning conditions were used as shown in Figure 1. In the first set up, the fibres were simply extruded at varying extrusion velocities $\left(V_{1}\right)$ and were immediately coagulated without fibre winding (Figure 1a). In the second set up, the cellulose/MWNTs solution dope was injected into water bath at fixed extrusion velocity $\left(V_{1}\right)$, while the winding drum and electric motor were continuously winding the fibres at varying winding velocities $\left(V_{2}\right)$ downstream (Figure $\left.1 b\right)$. The first series of fibres were manufactured without winding $\left(V_{2}=0\right)$ using different extrusion speeds $\left(V_{1}\right)$ 


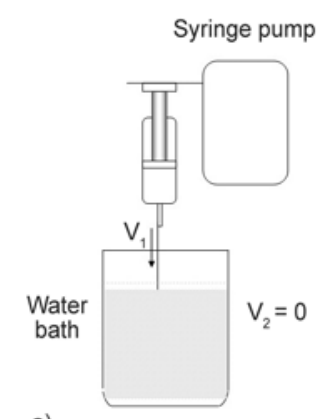

a)

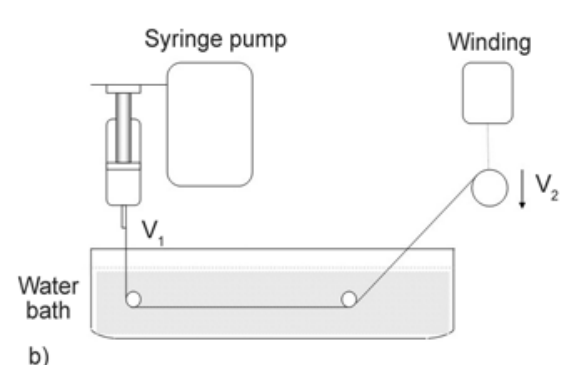

b)

Figure 1. Spinning equipment for (a) the first series of cellulose/MWNTs fibres and (b) the second series of cellulose/ MWNTs fibres

of $2.65 \cdot 10^{-3}, 5.3 \cdot 10^{-3}, 7.95 \cdot 10^{-3}$ and $1.06 \cdot 10^{-2} \mathrm{~m} / \mathrm{s}$. The second series of fibres was manufactured using a constant extrusion speed of $V_{1}=5.3 \cdot 10^{-3} \mathrm{~m} / \mathrm{s}$ with different winding speeds $\left(V_{2}\right)$ of 0 and $2.5 \cdot 10^{-2} \mathrm{~m} / \mathrm{s}$. The air gap between the nozzle and water surface was $1 \mathrm{~cm}$. After spinning, the fibres were merged in distilled water for two days, with a change of water every $24 \mathrm{~h}$. Then the fibres were rolled and dried in a fume hood for a further $48 \mathrm{~h}$. For each kind of fibre, two $5 \mathrm{~mm}$ long lengths, $2 \mathrm{~mm}$ apart, were coated using conductive silver paint (Electrolube, UK). The painted fibres were dried at room temperature for $8 \mathrm{~h}$.

\subsection{Film preparation}

We kept fixed concentration of MWNTs ( 0.10 mass fraction) in cellulose/MWNTs film and fibre's preparation for comparison. There was no external shear or extensional force applied during processing in film preparation, thus the MWNTs dispersion in film could be considered as random status. The film study was carried out only as one special case where there was no external shear or extensional force applied during processing (unlike the fibre spinning process which involved both shear and extensional deformations of polymer solution).

For film preparation, we used 0.015 mass fraction cellulose to make low viscosity solution which was easily spread into a film. $0.075 \mathrm{~g}$ cellulose $(0.015$ mass fraction with respect to the total amount of $5 \mathrm{~g}$ EMIMAc) was added into $4.5 \mathrm{~g}$ EMIMAc in a $10 \mathrm{~mL}$ glass bottle and heated at $85^{\circ} \mathrm{C}$ with stirring at $10.5 \mathrm{rad} / \mathrm{s}$ for $2 \mathrm{~h}$. Then $0.5 \mathrm{~g}$ MWNTs/EMIMAc suspension ( 0.10 mass fraction MWNTs with respect to cellulose) was added into the cellulose/ EMIMAc solution and heated at $85^{\circ} \mathrm{C}$ with stirring at $10.5 \mathrm{rad} / \mathrm{s}$ for $2 \mathrm{~h}$.

After complete dissolution, the MWNTs/cellulose/ EMIMAc solution was poured into a $75 \mathrm{~mm}$ diame- ter glass petri dish to form a film, covering the bottom of the petri dish uniformly. The film was put in the hood at room temperature for $24 \mathrm{~h}$ to gel by absorbing moisture from the air. Then, the film was put into distilled water to remove the EMIMAc (water was changed every day). After two days, the film was dried in the hood at room temperature for 5 days.

Five pieces of rectangular films whose widths were about $5 \mathrm{~mm}$ were cut and labelled as Sample 1 through Sample 5. Two $5 \mathrm{~mm}$ long parts on each sample were coated using conductive silver paint (Electrolube, UK), leaving a $2 \mathrm{~mm}$ gap between them. The painted films were dried at room temperature for $8 \mathrm{~h}$.

\subsection{Characterization of cellulose/MWNTs films and fibres}

The width and height of the film sample were measured using a calliper. Three different locations' widths and heights were measured on the film to obtain the average width and height. The fibre's diameter was measured using a microscope. The microscopy analysis was carried out using a DMI 3000B microscope produced by Leica Microsystems CMS GmbH (Wetzlar, Germany) under TLBF (bright field transmitted light) method. Three photos on different locations were taken on the $2 \mathrm{~mm}$ long part of fibre between the two silver painted parts. For each microscope picture, three different locations' diameters were measured using the ImageJ software package. Thus, for all cellulose/MWNTs composite fibre samples, nine different locations' fibre diameters on the $2 \mathrm{~mm}$ long part were measured. The average diameter and the standard deviation were calculated and obvious die-swell behavior in first series of fibres with only extrusion is shown in Figure 2 [31]. 


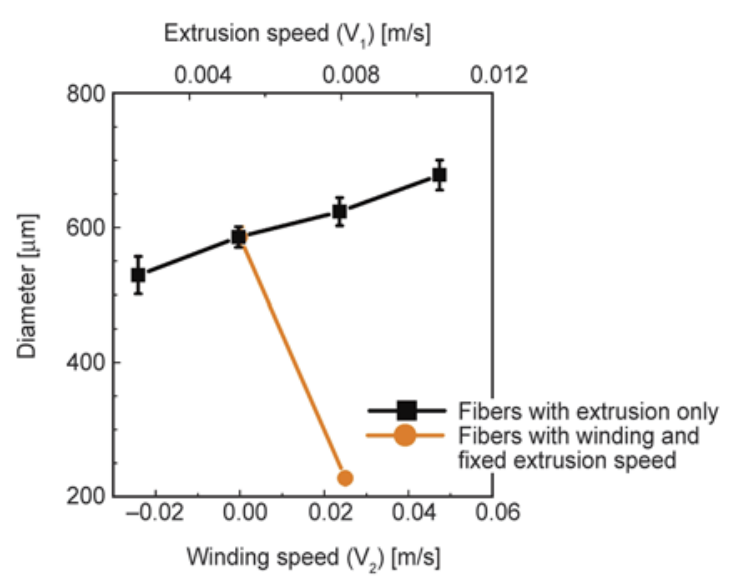

Figure 2. Fibre diameter measurements of cellulose/ MWNTs fibres as a function of extrusion speed and winding speed

The Fourier Transform Infrared Spectroscopy (FTIR) reflection was performed on a Spectrum 100 FTIR spectrometer (PerkinElmer). A total of 4 cumulative scans were taken, with a resolution of $4 \mathrm{~cm}^{-1}$, in the wavenumber range between 4000 to $650 \mathrm{~cm}^{-1}$ under absorbance mode.

The electrical conductivity testing was conducted with a 2-point conductivity rig to fix the samples and a precision LCR400 bridge (Thurlby Thandar instruments, UK). The two silver painted parts of films or fibres were fixed on the two copper points of the rig and the resistances of the $2 \mathrm{~mm}$ long fibres between the points were measured. The cellulose/MWNTs composite films and fibres' electrical conductivity were calculated using the Equation (1):

$$
\sigma=\frac{L}{R \cdot A}
$$

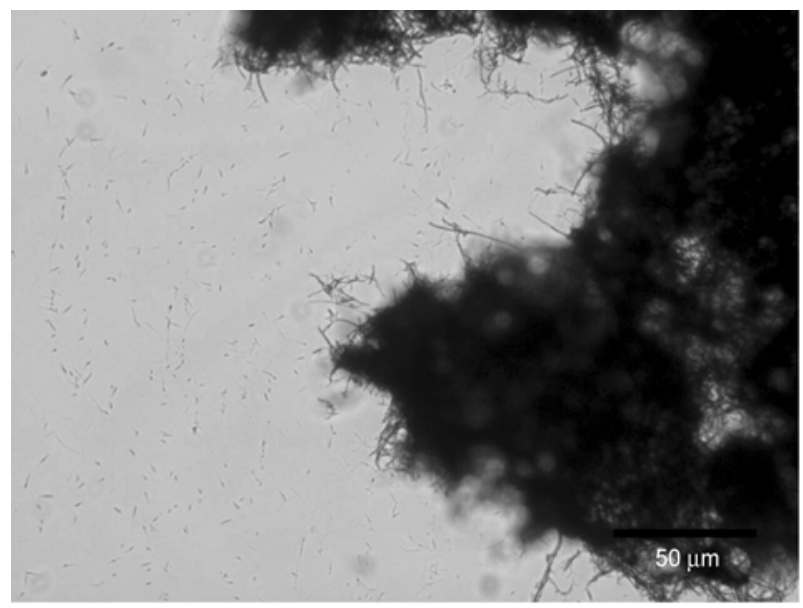

a) where $R$ is the resistance measured over length $L$, and $A$ is the cross-sectional area of the sample [32]. All samples for scanning electron microscope (SEM) analysis were prepared using Emitech K550 Sputter coater with 10 seconds of gold sputter coating. Both composite film and fibre samples were stretched and broken manually after cooling with liquid nitrogen. The cross-sectional areas of the samples were revealed and further observed by using JEOL 6340F.

Wide angle X-ray diffraction (WAXD) patterns were obtained using CCD \& X-ray photography, Generator 8, in University of Cambridge. It consists of an X-ray generator with c-tech XRD tube using $\mathrm{CuK}_{\alpha}$ radiation, a sample holder and a cassette with film inside to collect/detect the pattern. The machine ran at $40 \mathrm{kV}$ and $40 \mathrm{~mA}$, with 4-6 hours of exposure time to obtain the pattern on the film. The films were developed after exposure, dried and scanned to get digital pattern images. The pattern images were scanned using software of IDL to obtain both azimuthal and radial scanning data.

\section{Results and discussion}

\subsection{MWNTs dispersion in EMIMAc}

To manufacture cellulose/MWNTs composite fibres with uniform diameter, stable properties and experimental repeatability, the MWNTs need to have a good dispersion in cellulose/EMIMAc solution. $\mathrm{CMC}$ can be dissolved in both water and EMIMAc, and has been shown to debundle carbon nanotubes [33]. CMC is nonconductive, which may reduce the level of direct contact between MWNTs after coating, but can give MWNTs excellent uniform disper-

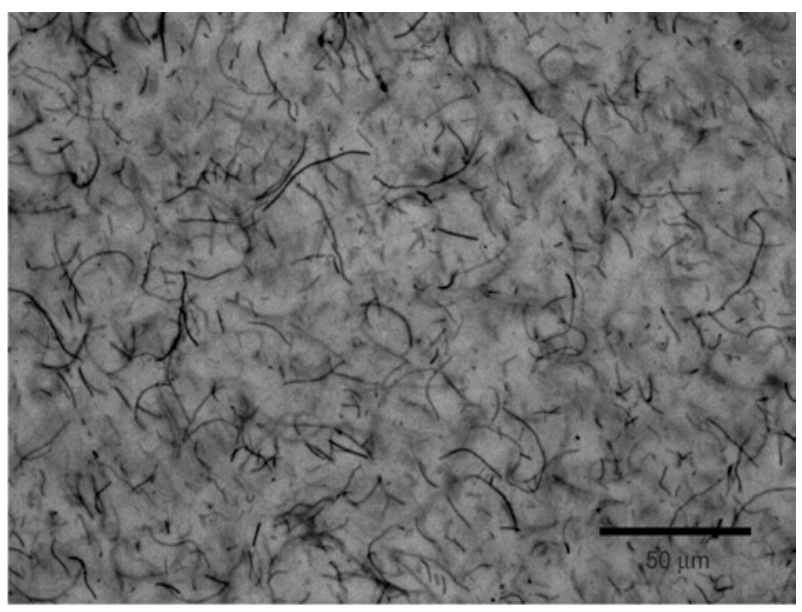

b)

Figure 3. Optical micrographs of MWNTs dispersion in EMIMAc (a) without CMC and (b) with CMC 
sion in EMIMAc and in cellulose fibres. The CMC coating of MWNTs improves the degree of MWNTs dispersion in cellulose which is a key requirement in developing a high quality nanocomposite product. Thus, we mixed CMC with MWNTs before adding MWNTs into EMIMAc. Figure 3a shows an optical micrograph of MWNTs dispersion without CMC coating and Figure $3 \mathrm{~b}$ shows the MWNTs dispersion with CMC coating. The CMC/MWNTs mixture had an excellent dispersion in EMIMAc. This is because the CMC can potentially form hydrogen bonds with EMIMAc, like cellulose, and coated the surfaces of MWNTs to avoid self-entanglement, both of which contribute to the improved dispersion in EMIMAc [33].

\subsection{FTIR analysis of raw cellulose and cellulose/MWNTs composite fibres}

FTIR analysis was used to confirm that EMIMAc was completely removed from cellulose/MWNTs fibres. The FTIR spectra of raw cellulose, cellulose/ MWNTs fibre and EMIMA are shown in Figure 4a. The hydrogen bond network inside raw cellulose was broken by EMIMAc leading to cellulose's dissolution [34, 35], and couldn't recover completely after cellulose's coagulation. The $\mathrm{CH}_{2}$ symmetric bending peak in the spectra (Figure 4b) weakened and shifted from 1427.6 to $1416.4 \mathrm{~cm}^{-1}$ after regeneration, indicating the destruction of the intramolecular hydrogen bond in $\mathrm{C}_{6}-\mathrm{OH}$ to some extent $[35,36]$. The typical function group $\mathrm{C}=\mathrm{N}\left(1562.7 \mathrm{~cm}^{-1}\right)$ of EMIMAc [37] is not present in cellulose/MWNTs fibre's spectrum (Figure 4c). This means that during coagulation process the majority of EMIMAc has been removed from fibres.

\subsection{Electrical conductivity measurement of cellulose/MWNTs composite film and fibres}

The electrical conductivity of cellulose/MWNTs fibres decreases as the extrusion speed $\left(V_{1}\right)$ increases as seen in Table 1 and Figure 5 (winding speed was kept to zero; $\left.V_{2}=0\right)$. The average conductivity of the cellulose/MWNTs composite film $\left(V_{1}=0\right)$ is $18.05 \mathrm{~S} / \mathrm{m}$, which is 75.2 times larger than the fibre with the slowest extrusion speed $\left(0.24 \mathrm{~S} / \mathrm{m} ; V_{1}=\right.$ $2.65 \cdot 10^{-3} \mathrm{~m} / \mathrm{s}$ ) and 501.4 times larger than the fibre with the fastest extrusion speed fibre $(0.036 \mathrm{~S} / \mathrm{m}$; $V_{1}=1.06 \cdot 10^{-2} \mathrm{~m} / \mathrm{s}$ ). The effect of winding speed on the reduction in the electrical conductivity of fibres was relatively small compared with the effect of extrusion speed (Table 1 and Figure 5). A modest decrease in conductivity (from 0.11 to $0.045 \mathrm{~S} / \mathrm{m}$ ) was observed due to winding the fibres after extrusion as seen in Figure 5.
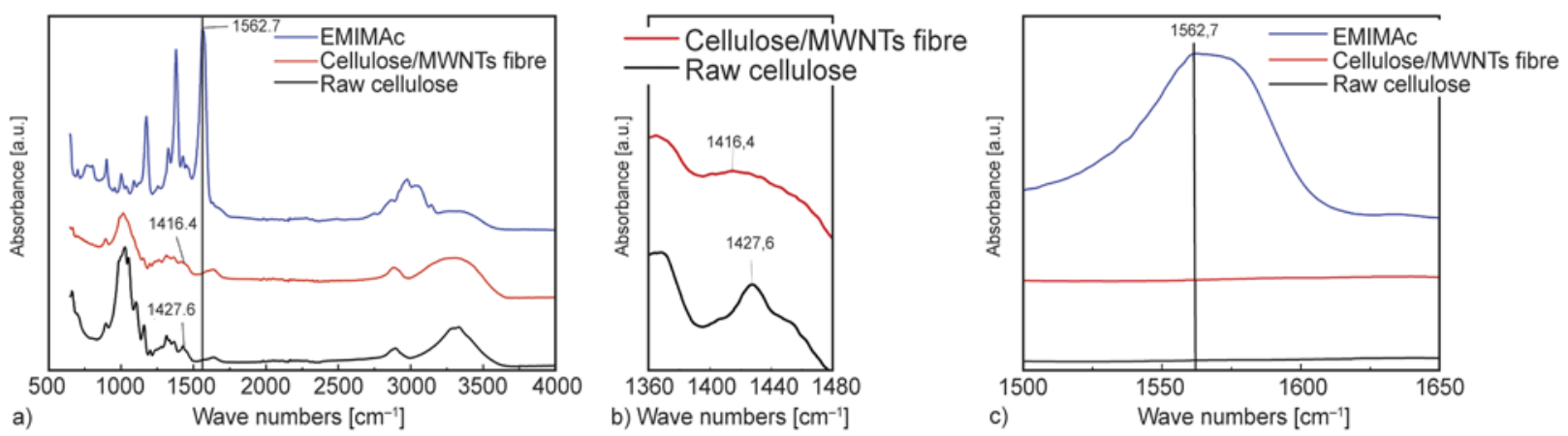

Figure 4. FTIR spectra of (a) raw cellulose, cellulose/MWNTs fibre and EMIMAc between $650-4000 \mathrm{~cm}^{-1}$, (b) raw cellulose and cellulose/MWNTs fibre between $1360-1480 \mathrm{~cm}^{-1}$ which show the weekended and shifted peak corresponding to $\mathrm{CH}_{2}\left(1427.6,1416.4 \mathrm{~cm}^{-1}\right)$ of cellulose after regeneration, and (c) raw cellulose, cellulose/MWNTs fibre and EMIMAc between $1500-1650 \mathrm{~cm}^{-1}$ which show absence of the peak corresponding to $\mathrm{C}=\mathrm{N}$ $\left(1562.7 \mathrm{~cm}^{-1}\right)$ of EMIMAc

Table 1. Conductivity and WAXD data for cellulose/MWNTs film and fibres

\begin{tabular}{|l|l|c|c|}
\hline \multirow{1}{*}{ Name } & \multicolumn{1}{|c|}{$\begin{array}{c}\text { Extrusion speed }\left(\mathbf{V}_{\mathbf{1}}\right) \text { and } \\
\text { winding speed }\left(\mathbf{V}_{\mathbf{2}}\right)\end{array}$} & $\begin{array}{c}\text { Conductivity } \\
{[\mathbf{S} / \mathbf{m}]}\end{array}$ & FWHM of MWNT (002) peak \\
\hline \multirow{4}{*}{ Film } & $V_{1}=0, \quad V_{2}=0$ & $18.050 \pm 3.490$ & 164.71 \\
\hline \multirow{4}{*}{ Fibre series 1 } & $V_{1}=2.65 \cdot 10^{-3} \mathrm{~m} / \mathrm{s}, \quad V_{2}=0$ & $0.239 \pm 0.019$ & - \\
\cline { 2 - 4 } & $V_{1}=5.30 \cdot 10^{-3} \mathrm{~m} / \mathrm{s}, \quad V_{2}=0$ & $0.112 \pm 0.016$ & 54.07 \\
\cline { 2 - 4 } & $V_{1}=7.96 \cdot 10^{-3} \mathrm{~m} / \mathrm{s}, \quad V_{2}=0$ & $0.080 \pm 0.010$ & - \\
\cline { 2 - 4 } & $V_{1}=1.06 \cdot 10^{-2} \mathrm{~m} / \mathrm{s}, \quad V_{2}=0$ & $0.036 \pm 0.021$ & 54.07 \\
\hline \multirow{2}{*}{ Fibre series 2 } & $V_{1}=5.30 \cdot 10^{-3} \mathrm{~m} / \mathrm{s}, \quad V_{2}=0$ & $0.112 \pm 0.016$ & 28.72 \\
\cline { 2 - 4 } & $V_{1}=5.3 \cdot 10^{-3} \mathrm{~m} / \mathrm{s}, \quad V_{2}=2.5 \cdot 10^{-2} \mathrm{~m} / \mathrm{s}$ & $0.045 \pm 0.009$ & \\
\hline
\end{tabular}




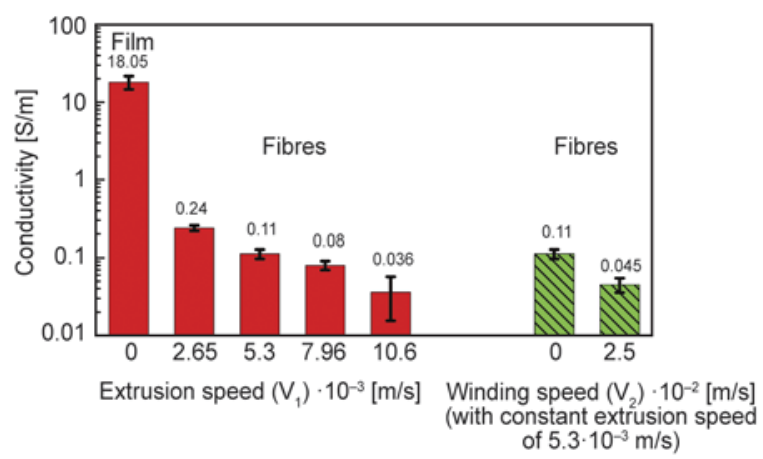

Figure 5. Conductivity of cellulose/MWNTs film and fibres with extrusion only, or with extrusion and winding

\subsection{SEM analysis of cellulose/MWNTs composite film and fibres}

SEM images of the composite film and fibre crosssections show MWNTs dispersion in cellulose (Figure 6). MWNTs appear to be oriented randomly in the composite the film (Figure 6a). However, the MWNTs show more alignment as the extrusion speed is increased (Figure 6b-6c).

SEM images of cellulose/MWNTs fibres' cross sections (Figure $6 b-6 c$ ), when the extrusion speed was very slow, show that MWNTs have a slight tendency to align along the fibre axis. As the extrusion and winding speeds increased, the alignment of MWNTs along fibre axis greatly increased. This means that during spinning, MWNTs dispersed well in EMIMAc and became aligned because of the shear and extensional force. This alignment is contributing to the decrease in fibre conductivity, because MWNTs are not in effective contact. The conducting pathways formed by contact between MWNTs through the fibre sample are reduced sig- nificantly due to the interval between orientated MWNTs as shown by previous theoretical work for electrical percolation of rigid rods [38]. Previous researchers have also reported alignment of carbon nanotubes during extrusion of polycarbonate and carbon nanotubes fibres using TEM analysis [39]. The decrease of conductivity due to alignment of nanofibres was also predicted in our previous studies using a combination of dissipative particle dynamics and Monte Carlo modelling method [40].

\subsection{X-ray analysis of aellulose/MWNTs composite film and fibres}

Figure 7 shows the WAXD radial scanning data (intensity against 2 $\theta$ ) of cellulose and MWNTs in a cellulose/MWNTs composite film and fibres at varying extrusion speeds. The diffraction patterns of these film and fibres correspond to the cellulose

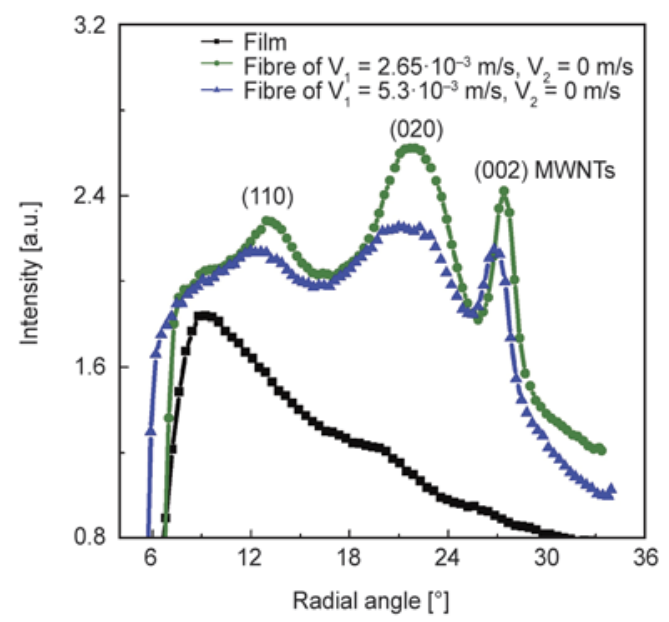

Figure 7. Integrated radial scans of cellulose/MWNTs film and fibres under different extrusion speeds without winding $\left(V_{1}=2.65 \cdot 10^{-3} \mathrm{~m} / \mathrm{s}, V_{2}=0 \mathrm{~m} / \mathrm{s} ; V_{1}=\right.$ $\left.5.3 \cdot 10^{-3} \mathrm{~m} / \mathrm{s}, V_{2}=0 \mathrm{~m} / \mathrm{s}\right)$

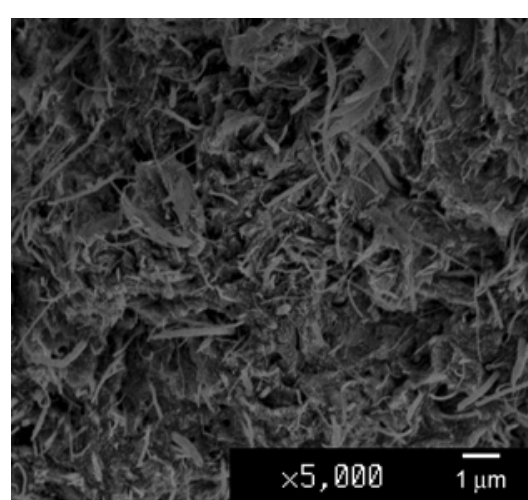

a)

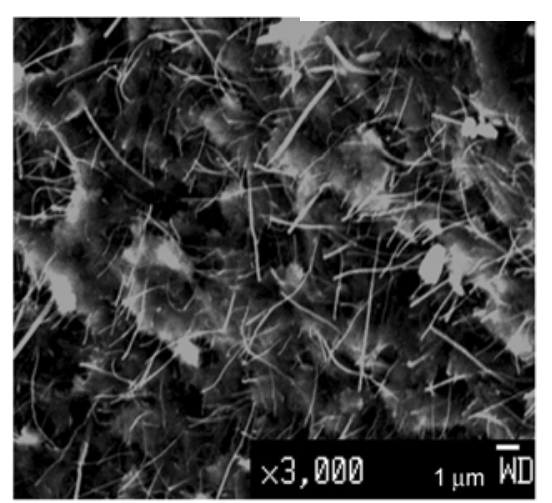

b)

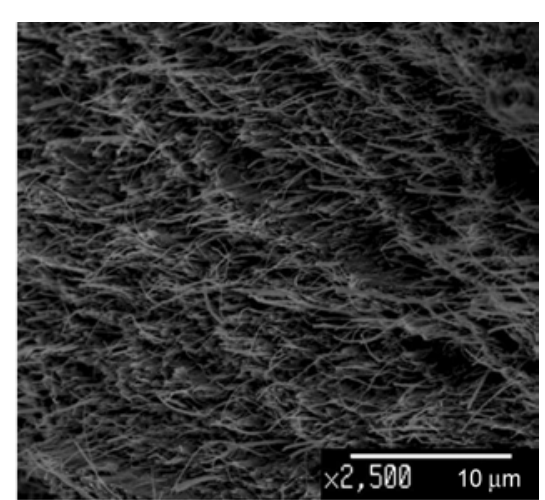

c)

Figure 6. SEM micrographs of stretched and broken cross sections of (a) cellulose/MWNTs film, (b) cellulose/MWNTs fibre with spinning speed of $V_{1}=5.3 \cdot 10^{-3} \mathrm{~m} / \mathrm{s}, V_{2}=0 \mathrm{~m} / \mathrm{s}$ and (c) cellulose/MWNTs fibre with spinning speed of $V_{1}=5.3 \cdot 10^{-3} \mathrm{~m} / \mathrm{s}, V_{2}=2.5 \cdot 10^{-2} \mathrm{~m} / \mathrm{s}$ 
II structure [41, 42], which is a widely known type of crystal structure of regenerated cellulose after its dissolution. In addition, the (002) graphitic peak at $2 \theta=26.8^{\circ}$ corresponding to MWNTs is also observed

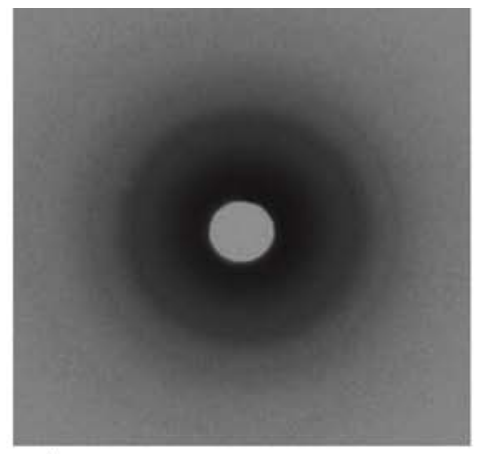

a)

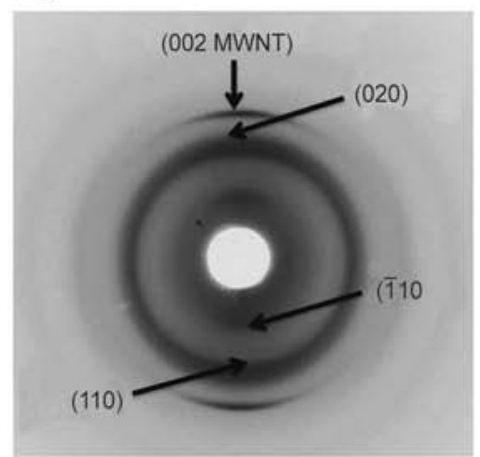

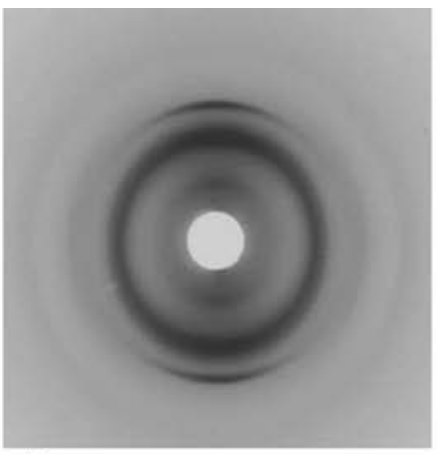

b)

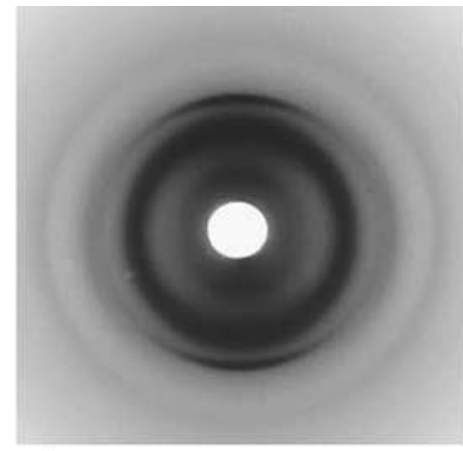

c)
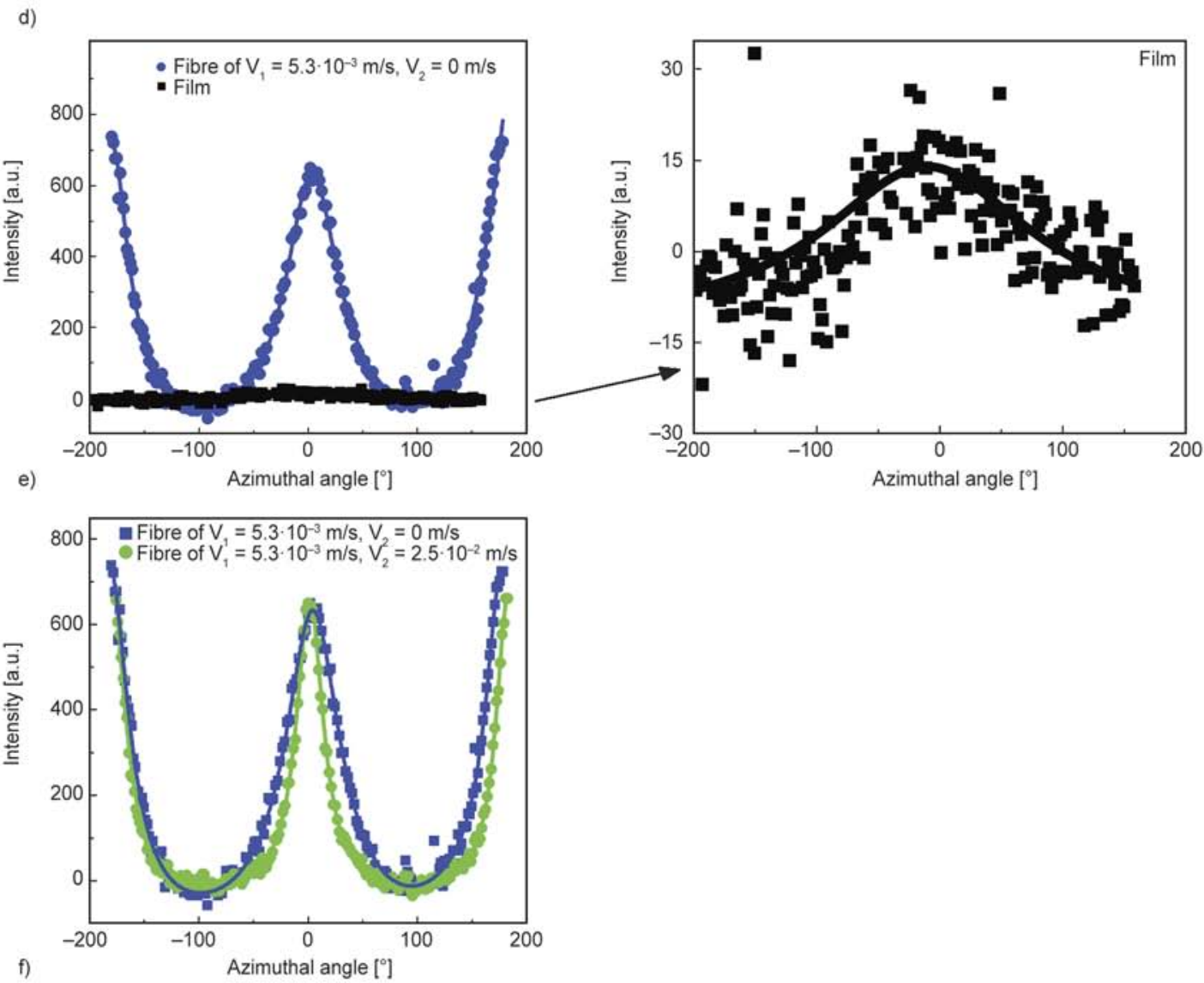

Figure 8. WAXD patterns of (a) cellulose/ MWNTs film, (b) cellulose/MWNTs fibres with speed of $V_{1}=2.65 \cdot 10^{-3} \mathrm{~m} / \mathrm{s}$, $V_{2}=0 \mathrm{~m} / \mathrm{s}$, (c) $V_{1}=5.3 \cdot 10^{-3} \mathrm{~m} / \mathrm{s}, V_{2}=0 \mathrm{~m} / \mathrm{s}$ and (d) $V_{1}=5.3 \cdot 10^{-3} \mathrm{~m} / \mathrm{s}, V_{2}=2.5 \cdot 10^{-2} \mathrm{~m} / \mathrm{s}$, and azimuthal scans of (e) cellulose/MWNTs fibres spun with different extrusion speeds without winding $\left(V_{1}=0 \mathrm{~m} / \mathrm{s}, V_{2}=0 \mathrm{~m} / \mathrm{s} ; V_{1}=\right.$ $5.3 \cdot 10^{-3} \mathrm{~m} / \mathrm{s}, V_{2}=0 \mathrm{~m} / \mathrm{s}$ ) as well as (f) cellulose/MWNTs fibres spun with different winding speeds and fixed extrusion speed $\left(V_{1}=5.3 \cdot 10^{-3} \mathrm{~m} / \mathrm{s}, V_{2}=0 \mathrm{~m} / \mathrm{s} ; V_{1}=5.3 \cdot 10^{-3} \mathrm{~m} / \mathrm{s}, V_{2}=2.5 \cdot 10^{-2} \mathrm{~m} / \mathrm{s}\right)$ 
in the composite fibres as expected $[8,43]$. The peaks at around $12^{\circ}$ correspond to cellulose (110) plane, whereas the peaks at around $22^{\circ}$ correspond to cellulose $(020)$ plane $[8,39,41]$.

Figure $8 \mathrm{a}-8 \mathrm{~d}$ show the two dimensional WAXD diffraction patterns of cellulose film and fibres spun at different spinning rates. SEM image of the film (Figure 6a) shows no alignment of MWNTs. Similarly WAXD data (Figure 8a and 8e) for film sample shows diffraction ring corresponding to MWNTs and hashas intensity uniformly distributed azimuthally along the circumference, which confirm no preferred orientation of MWNTs [43]. In a stretched fibre, the MWNTs have a preferred orientation with their longitudinal axes parallel to the strain direction, which appear as concentrated intensity in the diffraction ring in the azimuthal direction. The intensity of the diffraction ring becomes more anisotropic as the extrusion/winding speed increases, as shown in Figure $8 \mathrm{~b}-8 \mathrm{~d}$ [43]. Figure $8 \mathrm{e}-8 \mathrm{f}$ shows the azimuthal scans of MWNT (002) peak of these fibres. The full width at half maximum (FWHM) for MWNT (002) azimuthal scan is shown in Figure 8e, which decreases from 164.71 to 54.07 with increased extrusion speed from $0 \mathrm{~m} / \mathrm{s}$ (film, no extrusion) to $5.3 \cdot 10^{-3} \mathrm{~m} / \mathrm{s}$. The full width half $\max (\mathrm{FWHM})$ of 002 peak from MWNTs is a measure of degree of alignment of the MWNTs. The lower the value of FWHM, the higher is the degree of alignment of MWNTs, which is consistently observed with the increase in the extrusion and winding speeds of the composite fibre [44]. This confirms that the alignment of MWNTs in fibre increases as extrusion speed increases, which is the reason for the reduction in the conductivity of fibres as shown in Table 1. This observation is consistent with the SEM images for the cross-section of film and fibre composites. In Figure 8f, the FWHM for MWNT (002) azimuthal scan peak reduces from 54.07 to 28.72 as fibre winding speed increases from $0 \mathrm{~m} / \mathrm{s}$ to $2.5 \cdot 10^{-2} \mathrm{~m} / \mathrm{s}$. This confirms that the increased degree of MWNTs alignment is due to the increase in fibre winding speed.

\section{Conclusions}

In this paper we presented a novel method for uniform dispersion of MWNTs for manufacturing electrically conducting textiles. Dispersion of MWNTs is challenging due to their low surface energy. To address this problem we used non-covalent surface modification of MWNTs using CMC, which wraps around carbon nanotubes to enable good dispersion in water as well as ionic liquid (EMIMAc). This process modification allows us to use ionic liquid as a common platform to achieve good dispersion of MWNTs, as well as act as a benign solvent for spinning of cellulose nanocomposite fibres. To understand the effect of alignment of MWNTs due to shear and extensional deformation of fibre during spinning process, we systematically studied the change in the electrical properties of cellulose/ MWNT in two ways: as a function of extrusion speed without fibre winding/spinning, and as a function of fibre winding/spinning speed at constant extrusion speed. Increased extrusion speed causes a significant decrease in the electrical conductivity of the cellulose/MWNT fibre due to alignment of MWNTs, which results in reduced contact between MWNTs in the cellulose fibre matrix. The increased degree of alignment of MWNTs after extrusion and after fibre spinning/stretching was confirmed by SEM and WAXD studies. While it is important to produce textiles at high extrusion and winding speeds for increased productivity, it is clear from this study that in order to achieve good electrical conductivity the cellulose/MWNTs based smarts textiles need to be spun at moderately low speeds (extrusion speed such as $V_{1}=5.3 \cdot 10^{-3} \mathrm{~m} / \mathrm{s}$ ). The set of experiments carried out in the current work provide useful basic guideline for manufacturing of such smart textiles from cellulose/MWNTs composite fibres.

\section{Acknowledgements}

This work was supported by the Faculty of Engineering, the Centre for Nanoscience and Quantum Information (NSQI), the Faculty of Physics at the University of Bristol, and the Department of Materials Science \& Metallurgy at the University of Cambridge. Prof. Paul C. Trulove and J. W Gilman wish to acknowledge funding from the U.S. Air Force Office of Scientific Research.

A portion of this work was carried out by the National Institute of Standards and Technology (NIST), an agency of the U. S. government and by statute is not subject to copyright in the United States. Certain commercial equipment, instruments, materials, services, or companies are identified in this paper in order to specify adequately the experimental procedure. This in no way implies endorsement or recommendation by NIST. 


\section{References}

[1] Laxminarayana K., Jalili N.: Functional nanotubebased textiles: Pathway to next generation fabrics with enhanced sensing capabilities. Textile Research Journal, 75, 670-680 (2005).

DOI: $10.1177 / 0040517505059330$

[2] Llinás R., Mühlethaler M.: Electrophysiology of guineapig cerebellar nuclear cells in the in vitro brain stemcerebellar preparation. Journal of Physiology, 404, 241-258 (1988).

[3] Xie X-L., Mai Y-W., Zhou X-P.: Dispersion and alignment of carbon nanotubes in polymer matrix: A review. Materials Science and Engineering R: Reports, 49, 89-112 (2005). DOI: $10.1016 /$ j.mser.2005.04.002

[4] Rangari V. K., Shaik M. Y., Mahfuz H., Jeelani S.: Fabrication and characterization of high strength Nylon-6/ $\mathrm{Si}_{3} \mathrm{~N}_{4}$ polymer nanocomposite fibers. Materials Science and Engineering: A, 500, 92-97 (2009). DOI: 10.1016/j.msea.2008.09.014

[5] Zhang C., Yuan W., Wang S., Liang X.: Effect of MWCNTs irradiation grafting treatment on the surface properties of PBO fiber. Journal of Applied Polymer Science, 121, 3455-3459 (2011).

DOI: $10.1002 /$ app.33996

[6] Vankayala R. R., Lai W-J. P., Cheng K-C., Hwang K. C.: Enhanced electrical conductivity of nylon 6 composite using polyaniline-coated multi-walled carbon nanotubes as additives. Polymer, 52, 3337-3343 (2011). DOI: $10.1016 /$ j.polymer.2011.05.007

[7] Kumar S., Dang T. D., Arnold F. E., Bhattacharyya A. R., Min B. G., Zhang X., Vaia R. A., Park C., Adams W. W., Hauge R. H., Smalley R. E., Ramesh S., Willis P. A.: Synthesis, structure, and properties of $\mathrm{PBO} /$ SWNT composites. Macromolecules, 35, 9039-9043 (2002).

DOI: $10.1021 / \mathrm{ma} 0205055$

[8] Rahatekar S. S., Rasheed A., Jain R., Zammarano M., Koziol K. K., Windle A. H., Gilman J. W., Kumar S.: Solution spinning of cellulose carbon nanotube composites using room temperature ionic liquids. Polymer, 50, 4577-4583 (2009).

DOI: 10.1016/j.polymer.2009.07.015

[9] Fischer K., Hintze H., Schmidt I.: Reactivity of cellulose and characteristics of viscose. Papier, 50, 682687 (1996).

[10] Camacho F., González-Tello P., Jurado E., Robles A.: Microcrystalline-cellulose hydrolysis with concentrated sulphuric acid. Journal of Chemical Technology and Biotechnology, 67, 350-356 (1996).

DOI: $10.1002 /$ (sici)1097-4660(199612)67:4<350::aidjctb564>3.0.co;2-9

[11] Fink H-P., Weigel P., Purz H. J., Ganster J.: Structure formation of regenerated cellulose materials from NMMO-solutions. Progress in Polymer Science, 26, 1473-1524 (2001).

DOI: $10.1016 / \mathrm{s} 0079-6700(01) 00025-9$
[12] Heinze T., Schwikal K., Barthel S.: Ionic liquids as reaction medium in cellulose functionalization. Macromolecular Bioscience, 5, 520-525 (2005).

DOI: 10.1002/mabi.200500039

[13] El Seoud O. A., Koschella A., Fidale L. C., Dorn S., Heinze T.: Applications of ionic liquids in carbohydrate chemistry: A window of opportunities. Biomacromolecules, 8, 2629-2647 (2007).

DOI: $10.1021 / \mathrm{bm} 070062 \mathrm{i}$

[14] Kosan B., Michels C., Meister F.: Dissolution and forming of cellulose with ionic liquids. Cellulose, 15, 5966 (2008).

DOI: $10.1007 / \mathrm{s} 10570-007-9160-\mathrm{x}$

[15] Hermanutz F., Gähr F., Uerdingen E., Meister F., Kosan B.: New developments in dissolving and processing of cellulose in ionic liquids. Macromolecular Symposia, 262, 23-27 (2008).

DOI: $10.1002 /$ masy.200850203

[16] Haward S. J., Sharma V., Butts C. P., McKinley G. H., Rahatekar S. S.: Shear and extensional rheology of cellulose/ionic liquid solutions. Biomacromolecules, 13, 1688-1699 (2012).

DOI: $10.1021 / \mathrm{bm} 300407 \mathrm{q}$

[17] Swatloski R. P., Spear S. K., Holbrey J. D., Rogers R. D.: Dissolution of cellose with ionic liquids. Journal of the American Chemical Society, 124, 4974-4975 (2002).

DOI: $10.1021 / \mathrm{ja} 025790 \mathrm{~m}$

[18] Gericke M., Schlufter K., Liebert T., Heinze T., Budtova T.: Rheological properties of cellulose/ionic liquid solutions: From dilute to concentrated states. Biomacromolecules, 10, 1188-1194 (2009).

DOI: $10.1021 / \mathrm{bm} 801430 \mathrm{x}$

[19] Xie H., Li S., Zhang S.: Ionic liquids as novel solvents for the dissolution and blending of wool keratin fibers. Green Chemistry, 7, 606-608 (2005).

DOI: $10.1039 / \mathrm{b} 502547 \mathrm{~h}$

[20] Hameed N., Guo Q.: Blend films of natural wool and cellulose prepared from an ionic liquid. Cellulose, 17, 803-813 (2010). DOI: $10.1007 / \mathrm{s} 10570-010-9411-0$

[21] Qin Y., Lu X., Sun N., Rogers R. D.: Dissolution or extraction of crustacean shells using ionic liquids to obtain high molecular weight purified chitin and direct production of chitin films and fibers. Green Chemistry, 12, 968-971 (2010).

DOI: $10.1039 / \mathrm{c} 003583 \mathrm{a}$

[22] Barber P. S., Griggs C. S., Bonner J. R., Rogers R. D.: Electrospinning of chitin nanofibers directly from an ionic liquid extract of shrimp shells. Green Chemistry, 15, 601-607 (2013). DOI: $10.1039 / \mathrm{c} 2 \mathrm{gc} 36582 \mathrm{k}$

[23] Singh N., Koziol K. K. K., Chen J., Patil A. J., Gilman J. W., Trulove P. C., Kafienah W., Rahatekar S. S.: Ionic liquids-based processing of electrically conducting chitin nanocomposite scaffolds for stem cell growth. Green Chemistry, 15, 1192-1202 (2013). DOI: $10.1039 / \mathrm{c} 3 \mathrm{gc} 37087 \mathrm{a}$ 
[24] Silva S. S., Duarte A. R. C., Carvalho A. P., Mano J. F., Reis R. L.: Green processing of porous chitin structures for biomedical applications combining ionic liquids and supercritical fluid technology. Acta Biomaterialia, 7, 1166-1172 (2011). DOI: $10.1016 /$ j.actbio.2010.09.041

[25] Phillips D. M., Drummy L. F., Naik R. R., De Long H. C., Fox D. M., Trulove P. C., Mantz R. A.: Regenerated silk fiber wet spinning from an ionic liquid solution. Journal of Materials Chemistry, 15, 4206-4208 (2005).

DOI: $10.1039 / \mathrm{b} 510069 \mathrm{k}$

[26] Brandt A., Hallett J. P., Leak D. J., Murphy R. J., Welton T.: The effect of the ionic liquid anion in the pretreatment of pine wood chips. Green Chemistry, 12, 672-679 (2010).

DOI: $10.1039 / \mathrm{b} 918787 \mathrm{a}$

[27] Li C., Wang Q., Zhao Z. K.: Acid in ionic liquid: An efficient system for hydrolysis of lignocellulose. Green Chemistry, 10, 177-182 (2008).

DOI: $10.1039 / \mathrm{b} 711512 \mathrm{a}$

[28] Singh N., Rahatekar S. S., Koziol K. K. K., Ng T. S., Patil A. J., Mann S., Hollander A. P., Kafienah W.: Directing chondrogenesis of stem cells with specific blends of cellulose and silk. Biomacromolecules, 14, 1287-1298 (2013).

DOI: $10.1021 / \mathrm{bm} 301762 \mathrm{p}$

[29] Zhang H., Wang Z., Zhang Z., Wu J., Zhang J., He H.: Regenerated-cellulose/multiwalled- carbon-nanotube composite fibers with enhanced mechanical properties prepared with the ionic liquid 1-allyl-3-methylimidazolium chloride. Advanced Materials, 19, 698-704 (2007).

DOI: $10.1002 / \mathrm{adma} .200600442$

[30] Singh C., Shaffer M. S. P., Koziol K. K. K., Kinloch I. A., Windle A. H.: Towards the production of largescale aligned carbon nanotubes. Chemical Physics Letters, 372, 860-865 (2003). DOI: $10.1016 / \mathrm{s} 0009-2614(03) 00531-1$

[31] Liang J. Z.: Effects of extrusion conditions on dieswell behavior of polypropylene/diatomite composite melts. Polymer Testing, 27, 936-940 (2008).

DOI: 10.1016/j.polymertesting.2008.08.001

[32] Bradford P. D., Bogdanovich A. E.: Electrical conductivity study of carbon nanotube yarns, 3-D hybrid braids and their composites. Journal of Composite Materials, 42, 1533-1545 (2008). DOI: $10.1177 / 0021998308092206$

[33] Haggenmueller R., Rahatekar S. S., Fagan J. A., Chun J., Becker M. L., Naik R. R., Krauss T., Carlson L., Kadla J. F., Trulove P. C., Fox D. F., DeLong H. C., Fang Z., Kelley S. O., Gilman J. W.: Comparison of the quality of aqueous dispersions of single wall carbon nanotubes using surfactants and biomolecules. Langmuir, 24, 5070-5078 (2008).

DOI: $10.1021 / 1 \mathrm{a} 703008 \mathrm{r}$
[34] Remsing R. C., Swatloski R. P., Rogers R. D., Moyna G.: Mechanism of cellulose dissolution in the ionic liquid 1- $n$-butyl-3-methylimidazolium chloride: $\mathrm{A}{ }^{13} \mathrm{C}$ and ${ }^{35 / 37} \mathrm{Cl}$ NMR relaxation study on model systems. Chemical Communications, 2006, 1271-1273 (2006). DOI: $10.1039 / \mathrm{b} 600586 \mathrm{c}$

[35] Zhang H., Wu J., Zhang J., He J.: 1-allyl-3-methylimidazolium chloride room temperature ionic liquid: A new and powerful nonderivatizing solvent for cellulose. Macromolecules, 38, 8272-8277 (2005). DOI: $\underline{10.1021 / \mathrm{ma} 0505676}$

[36] Lan W., Liu C-F., Yue F-X., Sun R-C., Kennedy J. F.: Ultrasound-assisted dissolution of cellulose in ionic liquid. Carbohydrate Polymers, 86, 672-677 (2011). DOI: $10.1016 /$ j.carbpol.2011.05.013

[37] FitzPatrick M., Champagne P., Cunningham M. F.: Quantitative determination of cellulose dissolved in 1ethyl-3-methylimidazolium acetate using partial least squares regression on FTIR spectra. Carbohydrate Polymers, 87, 1124-1130 (2012).

DOI: $10.1016 /$ j.carbpol.2011.08.086

[38] Celzard A., McRae E., Deleuze C., Dufort M., Furdin G., Marêché J. F.: Critical concentration in percolating systems containing a high-aspect-ratio filler. Physical Review B, 53, 6209-6214 (1996).

DOI: 10.1103/PhysRevB.53.6209

[39] Pötschke P., Brünig H., Janke A., Fischer D., Jehnichen D.: Orientation of multiwalled carbon nanotubes in composites with polycarbonate by melt spinning. Polymer, 46, 10355-10363 (2005).

DOI: 10.1016/j.polymer.2005.07.106

[40] Rahatekar S. S., Hamm M., Shaffer M. S. P., Elliott J. A.: Mesoscale modeling of electrical percolation in fiber-filled systems. The Journal of Chemical Physics, 123, 134702/1-134702/5 (2005).

DOI: $10.1063 / 1.2031147$

[41] Qi H., Chang C., Zhang L.: Effects of temperature and molecular weight on dissolution of cellulose in $\mathrm{NaOH} /$ urea aqueous solution. Cellulose, 15, 779-787 (2008). DOI: 10.1007/s10570-008-9230-8

[42] Chen X., Burger C., Fang D., Ruan D., Zhang L., Hsiao B. S., Chu B.: X-ray studies of regenerated cellulose fibers wet spun from cotton linter pulp in $\mathrm{NaOH} /$ thiourea aqueous solutions. Polymer, 47, 2839-2848 (2006).

DOI: $10.1016 /$ j.polymer.2006.02.044

[43] Jin L., Bower C., Zhou O.: Alignment of carbon nanotubes in a polymer matrix by mechanical stretching. Applied Physics Letters, 73, 1197-1199 (1998). DOI: $10.1063 / 1.122125$

[44] Zhou W., Vavro J., Guthy C., Winey K. I., Fischer J. E., Ericson L. M., Ramesh S., Saini R., Davis V. A., Kittrell C., Pasquali M., Hauge R. H., Smalley R. E.: Single wall carbon nanotube fibers extruded from super-acid suspensions: Preferred orientation, electrical, and thermal transport. Journal of Applied Physics, 95, 649-655 (2004).

DOI: $\underline{10.1063 / 1.1627457}$ 